\title{
Glioblastoma stem cells and Wnt signaling pathway: molecular mechanisms and therapeutic targets
}

\author{
Ruoyu Guan', Xiaoming Zhang ${ }^{2}$ and Mian Guo ${ }^{1 *}$
}

\begin{abstract}
Glioblastoma is the most common form of primary brain tumor. Glioblastoma stem cells play an important role in tumor formation by activation of several signaling pathways. Wnt signaling pathway is one such important pathway which helps cellular differentiation to promote tumor formation in the brain. Glioblastoma remains to be a highly destructive type of tumor despite availability of treatment strategies like surgery, chemotherapy, and radiation. Advances in the field of cancer biology have revolutionized therapy by allowing targeting of tumor-specific molecular deregulation. In this review, we discuss about the significance of glioblastoma stem cells in cancer progression through Wnt signaling pathway and highlight the clinical targets being potentially considered for therapy in glioblastoma.
\end{abstract}

\section{Background}

Glioblastoma also known as glioblastoma multiforme (GBM) is one of the most lethal and commonly identified forms of brain tumor [1]. Around 80\% of the GBM tumors are located in the cerebral hemisphere $(<5 \%)$ located in the cerebellum, brain stem, and spinal cord [2]. GBM are malignant tumors commonly seen in 40-60-year-old individuals [3]. GBMs are often characterized by presence of glioblastoma stem cells (GSCs) [4], which are known to maintain their stemness through a number of signaling pathways [5, 6]. One of pathways gaining attention in GBM is the Wnt signaling. Wnt deregulation in brain is associated with congenital disorders [7], whereas it promotes malignancy in somatic cells of neuronal origin [8].

Wnt signaling pathway is mediated by Wnt family of 19 secreted glycoproteins (bearing22 or 24 cysteine residues) which are essential for cell proliferation, embryonic development, cell polarity, and tissue homeostasis [9]. There

\footnotetext{
* Correspondence: guomian@hrbmu.edu.cn

'Department of Neurosurgery, The Second Affiliated Hospital of Harbin Medical University, 246 Xuefu Road, Nangang, Harbin 150086, Heilongjiang Province, China

Full list of author information is available at the end of the article
}

are two Wnt pathways which determine the cell fate. Canonical Wnt signaling pathway is essential for embryonic development [10] and non-canonical Wnt pathway regulates cell movement and tissue polarity [11].

The current review focuses on the importance of Wnt signaling pathway in glioblastoma stem cell progression and explores targeting of Wnt signaling molecules as a potential therapy for glioblastoma.

\section{Glioblastoma stem cells}

Glioblastoma stem cells (GSCs) can differentiate into different cell types [12]. GSCs contribute to tumor growth and therapeutic resistance through multiple genetic and epigenetic modifications [4, 13-15]. Genetic modification in GSCs are observed in the form of promotion of angiogenesis [16], promotion of hypoxia through HIF signaling pathway [17], overexpression of surface marker such as SALL4 to inhibit apoptosis [18], or maintenance of multipotency through STAT3 regulation [19]. On the other hand, epigenetic modifications are also reported to be essential for proliferation and survival of GSCs [20]. Hypermethylation of specific genes are reportedly responsible for maintenance of stemness, GSC survival, faster GSC 
growth, and tumor promotion [21]. Additionally, several miRNAs are reported to induce invasion, migration, selfrenewal, stemness, and proliferation in GSCs [22].

\section{Glioblastoma stem cells and their resistance to chemotherapy and radiotherapy}

Chemotherapy and radiotherapy are commonly used adjuvant therapies in GBM patients who have undergone surgery. Despite treatment advances, GBM is associated with high recurrence and reduced time for patient survival [23]. GSCs are implicated for recurrence due to resistance to therapy, thereby allowing cell renewal and tumor re-initiation, while physically, GSCs are difficult to target because of their presence in the perivascular space [24]. At the molecular level, however, resistance to chemo- and radiotherapy is mediated through an aberrant expression of genes responsible for mismatch/base excision repair [25]. Additionally, the role of overexpressed ABC transporters [26] chromatin remodeling [27] and epigenetic modifications at the transcriptional level have also been postulated [28].

The GSC-associated resistance to therapy in GBM is addressed through a triaged approach: one which physically allows drug targets to effectively reach the cells through change in tumor microenvironment [29-33], second which targets GSCs [34, 35] or makes GSCs more susceptible to therapy [36-41], and third through epigenetic modification in GSCs allowing change in tumor characteristics [42-45] such as reduced sphere formation, induction of cellular apoptosis, and prevention of cellular proliferation.

\section{Wnt signaling pathway}

\section{Canonical Wnt signaling pathway and non-canonical Wnt} signaling pathway

Wnt signaling is known as an important regulator of intercellular interaction, cell fate decision, and migration. Developmental defects are attributed to mutations in the critical components of Wnt signaling whereas aberrant Wnt signaling is associated with cancers. Canonical Wnt components bind to cell surface receptors namely frizzled receptor (FZD) and activate low-density lipoprotein receptor-related protein 5, 6 (LRP5/6) complex. Activation of these receptors leads to destabilization of complex consisting of adenomatous polyposis coli (APC), glycogen synthase kinase-3 (GSK3), and Axin [46]. This stabilizes $\beta$-catenin, which then travels to nucleus, complexes with $\mathrm{T}$ cell factor/lymphocyte enhancer factor, and activates Wnt target genes namely, c-myc, cyclin-D, and VEGF which are important for embryonic development [47-49].

Wnt non-canonical pathway consists of two different pathways depending on the mediators. Disheveled (DVL)-c-jun $\mathrm{N}$ terminal kinase (JNK) pathway/planar cell polarity pathway involved in cellular polarity. Binding of wnt to FZD via DVL, JNK kinase activates the pathway responsible for changes in cytoskeleton [50]. The second non-canonical pathway is $\mathrm{Ca}^{2+}$-mediated pathway where binding of wnt protein to FZD receptors activates DVL and phospholipase C (PLC) followed by activation of inositol 1,4,5-triphosphate (IP3). IP3 interacts with $\mathrm{Ca}^{2+}$ channels in the endoplasmic reticulum and initiates the release of $\mathrm{Ca}^{2+}$ ions followed by activation of protein kinase $\mathrm{C}$ and cdc42, CAMKII, TAK1, NLK, and NFAT [51-53].

\section{Role of Wnt signaling pathway in glioblastoma and development of glioblastoma stem cells}

Aberrant Wnt signaling is found in various types of cancers. Activation of Wnt pathway is these tumors may be associated with mutations in sentinel components of the pathway viz, APC, $\beta$-catenin, AXIN, WTX, and TCF4. Wnt signaling mutations are most extensively characterized in colorectal cancers. It has been observed that close to $85 \%$ of colorectal tumors has a loss-of-function mutation in APC whereas 50\% of colorectal tumors which lack an APC mutation have activating mutation in $\beta$-catenin. Mutations in Wnt signaling components of colon cancer and medulloblastoma were found to be localized in $\beta$-catenin, APC, and AXIN1. Mutations of Wnt components are well characterized in various other cancers including hepatocellular carcinoma. Contrastingly, aberration of main components of Wnt pathway is not of common occurrence in GBM, ovarian, head and neck, breast, and gastric cancers $[54,55]$. However, recent reports from a small cohort have reported APC mutations in about $13 \%$ of GBM cases with a mutation frequency of close to $14.5 \%$ [56]. Another independent study identified a homozygous deletion in a negative regulator of Wnt pathway, namely, FAT atypical cadherin 1 (FAT1) [55]. While the role of FAT 1 in GBMs has been explored previously via the PDCD4 [57] and the HIF- $1 \alpha$ pathway [58], the study by Morris et al. [55] was the first to demonstrate the influence of FAT1 deletion on Wnt activation.

A recent study pointed to the role of proline-, glutamic acid-, and leucine-rich protein 1 (PELP1), a co-regulator of several nuclear receptor proteins, activating $\beta$ Catenin, thereby activating the Wnt signaling pathway. Overexpression of PELP1 was observed in $100 \%$ of the GBM samples [59].

In addition to the mutations in the main components constituting the Wnt pathway, few studies have also identified the role of epigenetic modifications that regulate Wnt pathway. One such study compared the Gene Expression Omnibus microRNA profiling of GBM versus the normal brain and found that $m i R-138-2-3 p$ and miR-770-5p were differentially expressed. These two 
have not been studied for their role in Wnt signaling aberration in GBMs, but their ability to modulate $\beta$ catenin has been ascertained in other cancers such as hepatocellular carcinoma and laryngeal cancers [60].

Long noncoding RNAs (lncRNA) namely HOX transcript antisense RNA (HOTAIR), nuclear enriched abundant transcript 1 (NEAT1), and maternally expressed gene 3 were negatively associated; differentiation antagonizing non-protein coding RNA (DANCR) was found to be positively affecting GBM progression through Wnt activation [61].

As discussed above, GBMs are driven by a subset of stem cells that self-renew and attribute tumor heterogeneity in addition to therapeutic resistance. However, the role of Wnt signaling in GBM stem cells remains poorly elucidated. For instance, A study showed that PLAGL2 contributed to stemness in GBM through activation of components of canonical pathway namely, WNT6, FZD9, and FZD2 [62]. Overexpression of PLAG L2 in GBM has also been confirmed. Another study found that the chromatin state in stem cells of GBM led to widespread activation of genes which were normally repressed. One such gene is the ASCL1, a transcription factor that activates Wnt signaling by repressing the negative regulator DKK1. In vivo studies have confirmed the role of ASCL1 in maintenance and tumorigenicity of GBM stem cells [63]. Another study by Adamo et al. found that GBM stem cells significantly overexpressed receptor-like tyrosine kinase (RYK). RYK overexpression influenced stemness frequency, cell migration, and invasion. RYK is postulated to promote stemness in GBM cells through stabilization of $\beta$-catenin [64].

Epigenetic modulation of Wnt pathway in GSCs has also been reported. lncRNA MIR22HG was found to be overexpressed in vitro in glioblastoma stem cell lines and has been functionally shown to be responsible for activation of Wnt signaling, by producing $m i R-22-3 p$ and $m i R-22-5 p$ [65]. Contrarily, expression of $m i R-34 a$ negatively correlates with patient survival in GBM. In vitro studies in GSCs have established the role of $m i R$ $34 a$ expression in targeted degradation of $\beta$-catenin. Although the role of $m i R-34 a$ in GSCs has already been established for notch signaling, its role as a modulator of the Wnt pathway has not been reported earlier [66].

While cursory studies exploring the activation of Wnt pathways in GBM and GSCs are reported, an in-depth study for identification of Wnt activators/deregulators either directly or through other pathways in GSCs remains elusive. The data remains further unexplored on patient-derived GSCs since most of these studies are in vitro models of GSC lines. Nevertheless, identification of these genetic or epigenetic modifications that result in aberrant Wnt expression in GSCs may serve as therapeutic or even as prognostic targets.
Crosstalk between Wnt and other signaling pathways

Wnt signaling pathway plays an important role in many human cancers. It has been reported that there is continuous activation of $\beta$-catenin in tumors though no mutations in the major components of the Wnt pathway or alterations in the signaling pathways. These findings confirm that there are others factors capable of activation of $\beta$-catenin and its downstream pathways [67]. Epidermal growth factor pathway is essential for motility, growth, proliferation, and differentiation of cells via tyrosine kinase signaling cascade. Overexpression of epidermal growth factor receptor (EGFR) is reported in many types of cancer. EGFR activation and nuclear translocation of $\beta$-catenin involves a kinase signaling cascade that leads to disassociation of $\beta$-catenin from $\alpha$-catenin. The free $\beta$-catenin translocates to the nucleus and increases tumor invasion [68]. HGF pathways are also found to crosstalk with Wnt signaling pathway. The receptor for HGF is c-met; binding of HGF to c-met phosphorylates $\beta$-catenin and translocates it to the nucleus [69]. Notch pathway is reported to repress Wnt pathway during development and homeostasis by associating with and regulating the transcription of $\beta$-catenin [70]. Similarly, activation of Wnt pathway antagonizes notch pathway through disheveled pathway leading to deregulation in cancer [71]. Elevated levels of Wnt signaling components in response to hedgehog pathway abnormalities and GLI1 expression are reported in cancer where elevated expression of GLI1 led to the accumulation of $\beta$ catenin in nucleus [72]. Hedgehog signaling pathway is also known to play an important role in overexpressing Wnt [73].

\section{Clinical applications of Wnt signaling pathway targets in glioblastoma}

Conventional multimodal treatment strategies employed for GBM have failed to prevent the recurrence and improve patient survival. While these strategies may have worked with other cancers, their failure in part, in GBM, is attributed to GSCs. The lack of therapeutic approach to prevent GSC renewal and promote tumorigenesis influences disease outcomes. Contrarily, targeting GSCs is challenging for its resemblance to normal neuronal stem/progenitor cells. We have reviewed studies which explore targeting GSCs in GBM and their implication on treatment outcome. An in vivo study by Almiron et al. targeted the hypoxic pathway in GSCs. Mice allografted with $S 100 \beta$-v-erbB $/ p 53^{-/-}$glioma stem-like cells were found to have increased survival and decreased cell renewal when treated with agents brefeldin A and EHT1864 [74].

KDM2B, JmjC domain histone H3K36me2/me1 demethylase, the chromatin regulator, is highly expressed in GBM and plays a role in GSC survival by modulating $\beta$ - 
catenin stability. In vitro studies on patient-derived GBM cells demonstrate that genetic or pharmacological inhibition (GSKJ4) of KDM2B results in a decrease of GSC pool along with increased sensitivity to chemotherapy [75]. Several articles have reviewed the targeting of Wnt signaling in GSCs which may be reviewed [76, 77].

\section{Wnt pathway alteration in GBM}

The existing literature establishes that Wnt plays a significant role in maintaining stemness of normal stem cells thereby allowing repair and regeneration. However, a deregulated Wnt pathway may result in onset of cancer stem cells which eventually results in enlarged tumor mass and proliferation. Despite evidence to the deregulation of Wnt pathway in GBM-associated GSC, the large number of ligands and receptors for either canonical or non-canonical Wnt pathways or cross talking pathways makes systematic classification difficult. However, from currently reviewed studies, it is evident that direct mutations in components of Wnt signaling pathway (APC, $\beta$-catenin, AXIN, and TCF4) are not significantly reported. Alternatively, genetic or epigenetic modulation of regulatory pathways influencing Wnt signaling in GSCs is more routinely reported. With new evidence, initial impressions may be changing and thus the significance of Wnt signaling deregulation in generation of GSC in GBM cannot be disregarded.

\section{Conclusions}

GBM is the most lethal form of gliomas involving GSCs. GSCs undergo differentiation, cell proliferation, and selfrenewal and maintain stemness by following many signaling pathways. Of these pathways, Wnt signaling pathway is important for differentiation of GSCs. Aberrant Wnt signaling in GSCs renders them resistant to conventional chemo- and radiotherapy thereby making it necessary to assess the efficacy of alternate treatment strategies. While these strategies are experimental in nature, their medical application is limited. The hindrance is the heterogeneity associated with the plasticity of GSC surface markers making recognition and thus targeting of therapy difficult. Additionally, addressing the challenge of similarity between normal neuronal stem cells and GSCs makes treatment-associated toxicity a plausibility. It is suggested that a combinatorial approach which allows cellular targeting of Wnt signaling such as CAR T-mediated drug delivery may be considered to address the challenge.

\footnotetext{
Abbreviations

GBM: Glioblastoma multiforme; GSCs: Glioblastoma stem cells; FZD: Frizzled receptor; LRP5/6: Lipoprotein receptor-related protein 5, 6;

APC: Adenomatous polyposis coli; GSK3: Glycogen synthase kinase-3; DVL: Disheveled; JNK: Jun N terminal kinase; PLC: Phospholipase C; IP3: Inositol 1,4,5-triphosphate; FAT1: FAT atypical cadherin 1; PELP1: Leucinerich protein 1; IncRNA: Long noncoding RNAs; HOTAIR: HOX transcript antisense RNA; NEAT1: Nuclear enriched abundant transcript 1; DANC
}

R: Differentiation antagonizing non-protein coding RNA; RYK: Receptor-like tyrosine kinase; EGFR: Epidermal growth factor receptor; GSKJ4: Genetic or pharmacological inhibition

\section{Acknowledgements \\ Not applicable.}

Authors' contributions

GR wrote the manuscript. MG designed the work and revised the manuscript All authors read and approved the final manuscript.

\section{Funding}

This work was supported by the National Natural Science Foundation of China (no. 81773161 and 81572472).

\section{Availability of data and materials}

All relevant data are within the manuscript.

Ethics approval and consent to participate

Not applicable.

\section{Consent for publication}

Not applicable.

\section{Competing interests}

The authors declare that they have no competing interests.

\section{Author details}

'Department of Neurosurgery, The Second Affiliated Hospital of Harbin Medical University, 246 Xuefu Road, Nangang, Harbin 150086, Heilongjiang Province, China. ${ }^{2}$ Department of Neurology, The Second Affiliated Hospital of Harbin Medical University, Harbin 150081, Heilongjiang Province, China.

Received: 10 February 2020 Accepted: 6 July 2020

Published online: 03 August 2020

\section{References}

1. Sattiraju A, Sai KKS, Mintz A. Glioblastoma stem cells and their microenvironment. Adv Exp Med Biol. 2017;1041:119-40.

2. Nakada M, Kita D, Watanabe T, Hayashi Y, Teng L, Pyko IV, Hamada J. Aberrant signaling pathways in glioma. Cancers (Basel). 2011;3(3):3242-78.

3. Louis DN, Ohgaki H, Wiestler OD, Cavenee WK, Burger PC, Jouvet A, Scheithauer BW, Kleihues P. The 2007 WHO classification of tumours of the central nervous system. Acta Neuropathol. 2007;114(2):97-109.

4. Cruceru ML, Neagu M, Demoulin JB, Constantinescu SN. Therapy targets in glioblastoma and cancer stem cells: lessons from haematopoietic neoplasms. J Cell Mol Med. 2013;17(10):1218-35.

5. Liebelt BD, Shingu T, Zhou X, Ren J, Shin SA, Hu J. Glioma stem cells: signaling, microenvironment, and therapy. Stem Cells Int. 2016;2016: 7849890 .

6. Cheng L, Bao S, Rich JN. Potential therapeutic implications of cancer stem cells in glioblastoma. Biochem Pharmacol. 2010;80(5):654-65.

7. Thomas KR, Capecchi MR. Targeted disruption of the murine int-1 protooncogene resulting in severe abnormalities in midbrain and cerebellar development. Nature. 1990;346(6287):847-50.

8. Bhavanasi D, Klein PS. Wht signaling in normal and malignant stem cells. Current Stem Cell Reports. 2016;2(4):379-87.

9. Logan CY, Nusse R. The Wnt signaling pathway in development and disease. Annu Rev Cell Dev Biol. 2004;20:781-810.

10. Nam JS, Turcotte TJ, Smith PF, Choi S, Yoon JK. Mouse cristin/R-spondin family proteins are novel ligands for the Frizzled 8 and LRP6 receptors and activate beta-catenin-dependent gene expression. J Biol Chem. 2006; 281(19):13247-57.

11. Komiya Y, Habas R. Wnt signal transduction pathways. Organogenesis. 2008; 4(2):68-75.

12. Heddleston JM, Li Z, McLendon RE, Hjelmeland AB, Rich JN. The hypoxic microenvironment maintains glioblastoma stem cells and promotes reprogramming towards a cancer stem cell phenotype. Cell cycle (Georgetown, Tex). 2009;8(20):3274-84. 
13. Huang Z, Cheng L, Guryanova OA, Wu Q, Bao S. Cancer stem cells in glioblastoma--molecular signaling and therapeutic targeting. Protein Cell. 2010;1(7):638-55.

14. Gilbert CA, Ross AH. Cancer stem cells: cell culture, markers, and targets for new therapies. J Cell Biochem. 2009;108(5):1031-8.

15. Schiffer D, Mellai M, Annovazzi L, Caldera V, Piazzi A, Denysenko T, Melcarne A. Stem cell niches in glioblastoma: a neuropathological view. BioMed Res Int. 2014;2014:725921.

16. Mei X, Chen YS, Chen FR, Xi SY, Chen ZP. Glioblastoma stem cell differentiation into endothelial cells evidenced through live-cell imaging. Neuro-oncology. 2017;19(8):1109-18.

17. Seidel S, Garvalov BK, Wirta V, von Stechow L, Schanzer A, Meletis K, Wolter M, Sommerlad D, Henze AT, Nister M, et al. A hypoxic niche regulates glioblastoma stem cells through hypoxia inducible factor 2 alpha. Brain : a journal of neurology. 2010;133(Pt 4):983-95.

18. Zbinden M, Duquet A, Lorente-Trigos A, Ngwabyt SN, Borges I, Ruiz i Altaba A. NANOG regulates glioma stem cells and is essential in vivo acting in a crossfunctional network with GLI1 and p53. The EMBO journal. 2010;29(15):2659-74.

19. Sherry MM, Reeves A, Wu JK, Cochran BH. STAT3 is required for proliferation and maintenance of multipotency in glioblastoma stem cells. Stem cells (Dayton, Ohio). 2009:27(10):2383-92.

20. Nabilsi NH, Deleyrolle LP, Darst RP, Riva A, Reynolds BA, Kladde MP. Multiplex mapping of chromatin accessibility and DNA methylation within targeted single molecules identifies epigenetic heterogeneity in neural stem cells and glioblastoma. Genome Res. 2014;24(2):329-39.

21. Lee EJ, Rath P, Liu J, Ryu D, Pei L, Noonepalle SK, Shull AY, Feng Q, Litofsky NS, Miller DC et al: Identification of global DNA methylation signatures in glioblastoma-derived cancer stem cells. J Genet Genomics = Yi chuan xue bao 2015, 42(7):355-371.

22. Safa AR, Saadatzadeh MR, Cohen-Gadol AA, Pollok KE, Bijangi-Vishehsaraei K. Glioblastoma stem cells (GSCS) epigenetic plasticity and interconversion between differentiated non-GSCs and GSCs. Genes Dis. 2015;2(2):152-63.

23. Auffinger $B$, Spencer $D$, Pytel $P$, Ahmed AU, Lesniak MS. The role of glioma stem cells in chemotherapy resistance and glioblastoma multiforme recurrence. Expert Rev Neurother. 2015;15(7):741-52.

24. Ahmed AU, Auffinger B, Lesniak MS. Understanding glioma stem cells: rationale, clinical relevance and therapeutic strategies. Expert Rev Neurother. 2013;13(5):545-55

25. Liu G, Yuan X, Zeng Z, Tunici P, Ng H, Abdulkadir IR, Lu L, Irvin D, Black KL, Yu JS. Analysis of gene expression and chemoresistance of CD133+ cancer stem cells in glioblastoma. Molecular cancer. 2006;5:67.

26. Bleau AM, Hambardzumyan D, Ozawa T, Fomchenko El, Huse JT, Brennan CW, Holland EC. PTEN/PI3K/Akt pathway regulates the side population phenotype and ABCG2 activity in glioma tumor stem-like cells. Cell stem cell. 2009;4(3):226-35.

27. Wang M, Han J, Marcar L, Black J, Liu Q, Li X, Nagulapalli K, Sequist LV, Mak $\mathrm{RH}$, Benes $\mathrm{CH}$, et al. Radiation resistance in KRAS-mutated lung cancer is enabled by stem-like properties mediated by an osteopontin-EGFR pathway. Cancer research. 2017;77(8):2018-28.

28. Nagarajan RP, Costello JF. Epigenetic mechanisms in glioblastoma multiforme. Seminars in cancer biology. 2009;19(3):188-97.

29. Teodorczyk M, Schmidt MHH. Notching on cancer's door: notch signaling in brain tumors. Front Oncol. 2014:4:341

30. Galan-Moya EM, Le Guelte A, Lima Fernandes E, Thirant C, Dwyer J, Bidere N, Couraud PO, Scott MG, Junier MP, Chneiweiss H, et al. Secreted factors from brain endothelial cells maintain glioblastoma stem-like cell expansion through the mTOR pathway. EMBO reports. 2011;12(5):470-6.

31. Ulasov IV, Nandi S, Dey M, Sonabend AM, Lesniak MS. Inhibition of Sonic hedgehog and Notch pathways enhances sensitivity of CD133(+) glioma stem cells to temozolomide therapy. Molecular medicine (Cambridge, Mass). 2011;17(1-2):103-12.

32. Liong C, Ortiz D, Ao-ieong E, Navati MS, Friedman JM, Cabrales P. Localized increase of tissue oxygen tension by magnetic targeted drug delivery. Nanotechnology. 2014;25(26):265102.

33. Gillespie DL, Aguirre MT, Ravichandran S, Leishman LL, Berrondo C, Gamboa JT, Wang $L$, King $R$, Wang $X$, Tan $M$, et al. RNA interference targeting hypoxia-inducible factor 1alpha via a novel multifunctional surfactant attenuates glioma growth in an intracranial mouse model. J Neurosurg. 2015;122(2):331-41.

34. Wang $\mathrm{CH}$, Chiou $\mathrm{SH}$, Chou $\mathrm{CP}$, Chen YC, Huang YJ, Peng CA Photothermolysis of glioblastoma stem-like cells targeted by carbon nanotubes conjugated with CD133 monoclonal antibody. Nanomedicine. 2011;7(1):69-79.

35. Wu ZB, Qiu C, Zhang AL, Cai L, Lin SJ, Yao Y, Tang QS, Xu M, Hua W, Chu YW, et al. Glioma-associated antigen HEATR1 induces functional cytotoxic T lymphocytes in patients with glioma. J Immunol Res. 2014;2014:131494.

36. Li WO, Li YM, Tao BB, Lu YC, Hu GH, Liu HM, He J, Xu Y, Yu HY. Downregulation of ABCG2 expression in glioblastoma cancer stem cells with miRNA-328 may decrease their chemoresistance. Med Sci Monit. 2010; 16(10):Hy27-30

37. Martin V, Sanchez-Sanchez AM, Herrera F, Gomez-Manzano C, Fueyo J, Alvarez-Vega MA, Antolin I, Rodriguez C. Melatonin-induced methylation of the ABCG2/BCRP promoter as a novel mechanism to overcome multidrug resistance in brain tumour stem cells. Brit J Cancer. 2013;108(10):2005-12.

38. Wu J, Lai G, Wan F, Xiao Z, Zeng L, Wang X, Ye F, Lei T. Knockdown of checkpoint kinase 1 is associated with the increased radiosensitivity of glioblastoma stem-like cells. Tohoku J Exp Med. 2012;226(4):267-74.

39. Nadkarni A, Shrivastav M, Mladek AC, Schwingler PM, Grogan PT, Chen J, Sarkaria JN. ATM inhibitor KU-55933 increases the TMZ responsiveness of only inherently TMZ sensitive GBM cells. J Neuro-oncol. 2012;110(3):349-57.

40. King HO, Brend T, Payne HL, Wright A, Ward TA, Patel K, Egnuni T, Stead LF, Patel A, Wurdak H, et al. RAD51 Is a selective DNA repair target to radiosensitize glioma stem cells. Stem cell reports. 2017;8(1):125-39.

41. Aldea MD, Petrushev B, Soritau O, Tomuleasa Cl, Berindan-Neagoe I, Filip AG, Chereches G, Cenariu M, Craciun L, Tatomir C, et al. Metformin plus sorafenib highly impacts temozolomide resistant glioblastoma stem-like cells. J BUON. 2014;19(2):502-11.

42. Gal H, Pandi G, Kanner AA, Ram Z, Lithwick-Yanai G, Amariglio N, Rechavi G, Givol D. MIR-451 and Imatinib mesylate inhibit tumor growth of Glioblastoma stem cells. Biochem Biophys Res Comm. 2008;376(1):86-90.

43. Silber J, Lim DA, Petritsch C, Persson Al, Maunakea AK, Yu M, Vandenberg SR, Ginzinger DG, James CD, Costello JF, et al. miR-124 and miR-137 inhibit proliferation of glioblastoma multiforme cells and induce differentiation of brain tumor stem cells. BMC medicine. 2008;6:14.

44. Ernst A, Campos B, Meier J, Devens F, Liesenberg F, Wolter M, Reifenberger G, Herold-Mende C, Lichter P, Radlwimmer B. De-repression of CTGF via the miR-17-92 cluster upon differentiation of human glioblastoma spheroid cultures. Oncogene. 2010;29(23):3411-22.

45. Wang G, Shen J, Sun J, Jiang Z, Fan J, Wang H, Yu S, Long Y, Liu Y, Bao H, et al. Cyclophilin A maintains glioma-initiating cell stemness by regulating Wnt/beta-catenin signaling. Clin Cancer Res. 2017;23(21):6640-9.

46. Bejsovec A. Wnt signaling: an embarrassment of receptors. Current biology : CB. 2000;10(24):R919-22.

47. Mao J, Wang J, Liu B, Pan W, Farr GH 3rd, Flynn C, Yuan H, Takada S, Kimelman D, Li L, et al. Low-density lipoprotein receptor-related protein-5 binds to Axin and regulates the canonical Wnt signaling pathway. Molecular Cell. 2001;7(4):801-9.

48. Stamos JL, Weis WI. The beta-catenin destruction complex. Cold Spring Harb Perspect Biol. 2013;5(1):a007898.

49. MacDonald BT, Tamai K, He X. Wnt/beta-catenin signaling: components, mechanisms, and diseases. Developmental cell. 2009;17(1):9-26

50. Wang Y, Nathans J. Tissue/planar cell polarity in vertebrates: new insights and new questions. Development (Cambridge, England). 2007;134(4):647-58.

51. Sheldahl LC, Slusarski DC, Pandur P, Miller JR, Kuhl M, Moon RT. Dishevelled activates Ca2+ flux, PKC, and CamKIl in vertebrate embryos. J Cell Biol. 2003; 161(4):769-77.

52. Ishitani T, Kishida S, Hyodo-Miura J, Ueno N, Yasuda J, Waterman M, Shibuya H, Moon RT, Ninomiya-Tsuji J, Matsumoto K. The TAK1-NLK mitogenactivated protein kinase cascade functions in the Wnt-5a/Ca(2+) pathway to antagonize Wnt/beta-catenin signaling. Molecular Cellular Biol. 2003;23(1): $131-9$

53. Hogan PG, Chen L, Nardone J, Rao A. Transcriptional regulation by calcium, calcineurin, and NFAT. Genes Development. 2003:17(18):2205-32.

54. Nager M, Bhardwaj D, Canti C, Medina L, Nogues P. Herreros J: beta-catenin signalling in glioblastoma multiforme and glioma-initiating cells. Chemother Res Pract. 2012;2012:192362.

55. Morris LG, Kaufman AM, Gong Y, Ramaswami D, Walsh LA, Turcan S, Eng S, Kannan $K$, Zou Y, Peng L, et al. Recurrent somatic mutation of FAT1 in multiple human cancers leads to aberrant Wnt activation. Nature genetics. 2013;45(3):253-61

56. Tang C, Guo J, Chen H, Yao CJ, Zhuang DX, Wang Y, Tang WJ, Ren G, Yao Y, Wu JS, et al. Gene mutation profiling of primary glioblastoma through 
multiple tumor biopsy guided by $1 \mathrm{H}$-magnetic resonance spectroscopy. Int J Clin Exp Pathol. 2015;8(5):5327-35.

57. Dikshit B, Irshad K, Madan E, Aggarwal N, Sarkar C, Chandra PS, Gupta DK, Chattopadhyay P, Sinha S, Chosdol K. FAT1 acts as an upstream regulator of oncogenic and inflammatory pathways, via PDCD4, in glioma cells. Oncogene. 2013:32(33):3798-808.

58. Madan E, Dikshit B, Gowda SH, Srivastava C, Sarkar C, Chattopadhyay P, Sinha S, Chosdol K. FAT1 is a novel upstream regulator of HIF1alpha and invasion of high grade glioma. Int J Cancer. 2016;139(11):2570-82.

59. Sareddy GR, Pratap UP, Viswanadhapalli S, Venkata PP, Nair BC, Krishnan SR, Zheng S, Gilbert AR, Brenner AJ, Brann DW, et al. PELP1 promotes glioblastoma progression by enhancing Wnt/B-catenin signaling. NeuroOncology Advances. 2019:1(1).

60. Shaji SK, Sunilkumar D, Mahalakshmi NV, Kumar GB, Nair BG. Analysis of microarray data for identification of key microRNA signatures in glioblastoma multiforme. Oncology letters. 2019;18(2):1938-48.

61. Vecera M, Sana J, Lipina R, Smrcka M, Slaby O: Long non-coding RNAs in gliomas: from molecular pathology to diagnostic biomarkers and therapeutic targets. Int J Molecular Sci 2018, 19(9).

62. Zheng H, Ying H, Wiedemeyer R, Yan H, Quayle SN, Ivanova EV, Paik JH, Zhang H, Xiao Y, Perry SR, et al. PLAGL2 regulates Wnt signaling to impede differentiation in neural stem cells and gliomas. Cancer Cell. 2010;17(5):497-509.

63. Rheinbay E, Suva ML, Gillespie SM, Wakimoto H, Patel AP, Shahid M, Oksuz $\mathrm{O}$, Rabkin SD, Martuza RL, Rivera MN, et al. An aberrant transcription factor network essential for Wnt signaling and stem cell maintenance in glioblastoma. Cell reports. 2013;3(5):1567-79.

64. Adamo A, Fiore D, De Martino F, Roscigno G, Affinito A, Donnarumma E, Puoti I, Ricci Vitiani L, Pallini R, Quintavalle C et al: RYK promotes the stemness of glioblastoma cells via the WNT/beta-catenin pathway. Oncotarget 2017, 8(8):13476-13487.

65. Han M, Wang S, Fritah S, Wang X, Zhou W, Yang N, Ni S, Huang B, Chen A, $\mathrm{Li} G$, et al. Interfering with long non-coding RNA MIR22HG processing inhibits glioblastoma progression through suppression of Wht/beta-catenin signalling. Brain. 2020;143(2):512-30.

66. Rathod SS, Rani SB, Khan M, Muzumdar D, Shiras A. Tumor suppressive miRNA-34a suppresses cell proliferation and tumor growth of glioma stem cells by targeting Akt and Wnt signaling pathways. FEBS open bio. 2014;4: 485-95.

67. Thompson M, Nejak-Bowen K, Monga S. Crosstalk of the Wnt signaling pathway. In. 2011:51-80.

68. Ji H, Wang J, Nika H, Hawke D, Keezer S, Ge Q, Fang B, Fang X, Fang D, Litchfield DW, et al. EGF-induced ERK activation promotes CK2-mediated disassociation of alpha-Catenin from beta-Catenin and transactivation of beta-Catenin. Molecular cell. 2009;36(4):547-59.

69. Zeng G, Apte U, Micsenyi A, Bell A, Monga SP. Tyrosine residues 654 and 670 in beta-catenin are crucial in regulation of Met-beta-catenin interactions. Exp Cell Res. 2006;312(18):3620-30.

70. Hayward P, Brennan K, Sanders P, Balayo T, DasGupta R, Perrimon N, Martinez Arias A. Notch modulates Wnt signalling by associating with Armadillo/beta-catenin and regulating its transcriptional activity. Development (Cambridge, England). 2005;132(8):1819-30.

71. Axelrod JD, Matsuno K, Artavanis-Tsakonas S, Perrimon N. Interaction between Wingless and Notch signaling pathways mediated by dishevelled. Science (New York, NY). 1996;271(5257):1826-32.

72. Liao X, Siu MK, Au CW, Chan QK, Chan HY, Wong ES, Ip PP, Ngan HY, Cheung AN. Aberrant activation of hedgehog signaling pathway contributes to endometrial carcinogenesis through beta-catenin. Mod Pathol. 2009;22(6):839-47.

73. Katoh M, Katoh M. Transcriptional mechanisms of WNT5A based on NFkappaB, Hedgehog, TGFbeta, and Notch signaling cascades. Int J Molecular Med. 2009;23(6):763-9.

74. Almiron Bonnin DA, Havrda MC, Lee MC, Liu H, Zhang Z, Nguyen LN, Harrington LX, Hassanpour S, Cheng C, Israel MA. Secretion-mediated STAT3 activation promotes self-renewal of glioma stem-like cells during hypoxia. Oncogene. 2018;37(8):1107-18.

75. Staberg M, Rasmussen RD, Michaelsen SR, Pedersen H, Jensen KE, Villingshoj M, Skjoth-Rasmussen J, Brennum J, Vitting-Seerup K, Poulsen HS, et al. Targeting glioma stem-like cell survival and chemoresistance through inhibition of lysine-specific histone demethylase KDM2B. Molecular oncology. 2018;12(3):406-20.
76. Zuccarini M, Giuliani P, Ziberi S, Carluccio M, lorio PD, Caciagli F, Ciccarelli R. The role of Wnt signal in glioblastoma development and progression: a possible new pharmacological target for the therapy of this tumor. Genes. 2018:9(2).

77. Vengoji R, Ponnusamy MP, Rachagani S, Mahapatra S, Batra SK, Shonka N, Macha MA. Novel therapies hijack the blood-brain barrier to eradicate glioblastoma cancer stem cells. Carcinogenesis. 2019;40(1):2-14.

\section{Ready to submit your research? Choose BMC and benefit from:}

- fast, convenient online submission

- thorough peer review by experienced researchers in your field

- rapid publication on acceptance

- support for research data, including large and complex data types

- gold Open Access which fosters wider collaboration and increased citations

- maximum visibility for your research: over $100 \mathrm{M}$ website views per year

At BMC, research is always in progress.

Learn more biomedcentral.com/submissions 